\title{
Aleitamento materno: desmistificando esse ato de amor como uma abordagem na promoção da saúde
}

Radmila Alves Alencar Viana*, Elany Gomes Ferreira**, Michelli Caroline de Camargo Barboza***, Luciana Mota de Andrade Sampaio****

* Acadêmica do PET-Saúde - Redes de Atenção à Saúde Materno Infantil e Graduanda em Fisioterapia pela Universidade de Fortaleza (UNIFOR)

** Graduanda em Fisioterapia pela Universidade de Fortaleza (UNIFOR)

*** Fisioterapeuta, Mestre em Saúde Coletiva pela Universidade de Fortaleza (UNIFOR), Docente da Universidade de Fortaleza (UNIFOR)

**** Fisioterapeuta, Mestre em Saúde Coletiva pela Universidade de Fortaleza (UNIFOR), Docente da Universidade de Fortaleza (UNIFOR)

\section{RESUMO}

Objetivo: Analisar as dificuldades vivenciadas pelas mães que influenciam na prática do aleitamento materno. Metodologia: Realizou-se um estudo descritivo com abordagem qualitativa desenvolvido em uma Instituição de ensino superior privada de Fortaleza - Ceará. Para coleta de informações aplicou-se um questionário sócio demográfico e entrevista semi-estruturada que aconteceu de agosto a outubro de 2013. Os dados foram analisados segundo a teoria de análise de conteúdos temáticos proposta por Bardin. Resultados: Participaram do estudo 15 mães na faixa etária entre 26 a 40 anos de diferentes perfis sócio econômicos e culturais. Destacou-se três categorias que emergiram das falas, agrupadas por convergência: Descobrindo o ato de amamentar; Vivências e sentimentos; e A hora do desmame. Conclusão: Observou-se que das dificuldades encontradas pelas mães destaca-se a dor, seguida pelas rachaduras, fissu- ras, cansaço e a produção reduzida de leite. O tempo de aleitamento materno exclusivo das entrevistadas foi inferior ao recomendado pelo Ministério da Saúde.

Descritores: Aleitamento Materno, Emoções, Desmame.

\section{INTRODUÇÃO}

O leite materno é o alimento ideal para o lactente devido as suas propriedades nutricionais e imunológicas, protegendo o recém-nascido de infecções, diarreia e doenças respiratórias, permitindo seu crescimento e desenvolvimento saudável, além de fortalecer o vinculo mãe-filho e reduzir o índice de mortalidade infantil. ${ }^{13}$

De acordo com um ensaio de evidências sobre os benefícios do aleitamento materno (AM) para a saúde da criança e da mulher, foram destacados que as crianças amamentadas apresentavam 
menor morbidade associada à diarreia e outras infecções e que para a saúde da mãe os benefícios era devido o retardo da menstruação, a rapidez da perda de peso no pósparto, a proteção para alguns tipos de câncer $^{21}$, a prevenção contra hemorragias, além do estímulo a involução uterina, minimizando assim, o risco de anemia. ${ }^{10}$

No Brasil, segundo dados da pesquisa Nacional de Demografia e Saúde da Criança e da Mulher, a prevalência de aleitamento materno exclusivo (AME) de zero a seis meses em 2006 era de $39,8 \%$ estando o seu período de duração e prevalência aquém do recomendado pela Organização Mundial em Saúde (OMS) e pelo Ministério da Saúde. ${ }^{13}$ De acordo com a II Pesquisa de Prevalência do AM nas Capitais Brasileiras e Distrito Federal, realizada em 2008, a prevalência do AME nos primeiros seis meses de vida foi de $41 \%{ }^{17}$

Apesar do discreto aumento da quantidade de crianças que foram amamentadas exclusivamente, o fato é que ainda existem muitas dificuldades que levam ao desmame precoce, alguns deles são, segundo um estudo de revisão crítica o trabalho materno fora do domicílio, as atividades diárias, a crença de que o leite materno não satisfaz; o incômodo, a falta de apoio dos familiares; o adoecimento da mãe ou do filho; problemas nas mamas, entre outras dificuldades. ${ }^{14}$

A Rede Cegonha, instituída no âmbito do Sistema Único de Saúde, consiste em uma rede de cuidados que visa assegurar à mulher o direito ao planejamento familiar e à atenção humanizada à gravidez, ao parto e ao puerpério, bem como à criança o direito ao nascimento seguro e ao crescimento e desenvolvimento saudáveis. Está organizada em quatro componentes: I - PréNatal; II - Parto e Nascimento; III - Puerpé- rio e Atenção Integral à Saúde da Criança; e IV - Sistema Logístico: Transporte Sanitário e Regulação. O Componente III dessa rede tem como ações a promoção do aleitamento materno e da alimentação complementar saudável. ${ }^{5}$

Portanto conhecer como as mães vivenciam o aleitamento materno, o tempo e o motivo do desmame são pontos importantes para trabalhar a promoção da saúde. Partindo das dificuldades e experiências relatadas pelas mães, a intervenção pode ser modificada a fim de favorecer uma relação mais prazerosa e duradora entre a díade mãe-bebê.

Definiu-se como objetivo, para o estudo, analisar as dificuldades vivenciadas pelas mães que influenciam na prática do aleitamento materno.

$\mathrm{O}$ interesse pela pesquisa se deu a partir da experiência no Pró/Pet-Saúde Atenção à Saúde Materno-Infantil (Rede Cegonha) em conhecer como as mães de diferentes perfis sócio econômicos e culturais vivenciam essa prática.

Acredita-se que a relevância do estudo se configura na possibilidade de transformações na assistência, educação e promoção em saúde, a partir da modificação do discurso oferecido às mães sobre o AM.

\section{MÉTODOS}

Realizou-se um estudo descritivo com abordagem qualitativa; desenvolvido em uma Instituição de ensino superior (IES) privada de Fortaleza - Ceará, que contempla cursos de graduação e pós-graduação nas áreas de ciências da comunicação e gestão, ciências jurídicas, ciências da saúde e ciências tecnológicas, contando também com uma grande quantidade de funcionários em funções administrativas e de serviços gerais. 
Foram selecionadas 15 mães puérperas, primíparas, por acreditar-se que a primeira experiência pode ser marcada por dúvidas e maiores adaptações e por ser ela decisiva para a instituição da prática do aleitamento materno; mães com filhos entre 06 e 24 meses de vida, por ser o período recomendado pelo Ministério da Saúde para o aleitamento e que tivessem amamentado independente do tempo.

A coleta foi realizada no período de agosto a outubro de 2013, através da aplicação de um questionário sócio demográfico e entrevista semi-estruturada. Inicialmente, foi realizado um contato com o setor de Recursos Humanos, para identificar as mulheres que estiveram de licença maternidade nos período referente aos dois últimos anos, essas foram escolhidas aleatoriamente e independente da função exercida.

A coleta de informações foi realizada através de entrevista individual e confidencial, em local reservado, sem interferências externas, não havendo limitação de tempo para a finalização da técnica. Após esse passo os relatos foram transcritos, incluindo as pausas e manifestações de emoção.

Um questionário sócio demográfico também foi aplicado nesse momento e contemplou os seguintes itens: identificação, nome, endereço, escolaridade materna, ocupação, idade da mãe, quantidade de filhos, estado civil, condição da habitação, renda familiar, fonte de renda, realizou prénatal, data da entrevista.

A entrevista semi-estruturada foi composta por 3 perguntas norteadoras: Como foi pra você amamentar seu filho? Por quanto tempo seu filho foi amamentado? Você teve alguma dificuldade para conseguir amamentar seu bebê? Foi utili- zado gravador para melhor registro das informações.

Os dados foram analisados segundo a teoria de análise de conteúdos temáticos proposta por Bardin, ${ }^{3}$ destacando-se três categorias que emergiram das falas, agrupadas por convergência, o que possibilitou a classificação do conteúdo em totalidade: Descobrindo o ato de amamentar; Vivências e sentimentos; e A hora do desmame. Por fim, foram interpretados os resultados obtidos, fase em que os discursos foram contextualizados, utilizando o referencial teórico como suporte para a análise.

Para a realização desta pesquisa, foi obedecida à Resolução 466/2012 do Conselho Nacional de Saúde, ${ }^{6}$ que regulamenta os aspectos ético-legais da pesquisa em seres humanos. O Número do Parecer Consubstanciado da pesquisa foi 376.620 autorizando a execução da mesma.

\section{RESULTADOS E DISCUSSÃO}

\subsection{Caracterização das mães}

O estudo foi realizado com 15 mães na faixa etária entre 26 a 40 anos, dentre elas a maioria possuía nível Superior Completo (9 mães), sendo 3 com pós-graduação lato sensu e 3 com pós-graduação stricto sensu, 2 tinham nível superior incompleto e 4 mães $2^{\circ}$ grau Completo. Quanto a ocupação das mesmas 7 delas atualmente são professoras da Universidade, 2 recepcionistas, 3 secretárias, 2 auxiliares de biblioteca e 1 auxiliar de serviços gerais.

Todas afirmaram possuir casa própria e apenas 1 era divorciada, 2 solteiras e as outras 12 eram casadas. Quanto à realização do pré-natal todas afirmaram ter realizado o pré-natal.

Nesse estudo será denominada como M1 a primeira mãe entrevistada e M15 a 
última mãe entrevista.

\subsection{Descobrindo o ato de amamentar}

A amamentação é um processo em que o lactente recebe o leite materno podendo ser feito de maneira exclusiva ou não. Será dita exclusiva quando o bebê receber apenas o leite da mama e não há adição de nenhum outro líquido ou sólido, exceto vitaminas, minerais ou medicamentos. 8

A decisão se o bebê será amamentar ou não, depende da mãe, das condições socioeconômicas, do conhecimento da importância que a mãe tem sobre essa prática, que aqui está diretamente relacionada ao nível de escolaridade materna, e das condições de saúde da mãe e do bebê.

Nesse momento entra o papel da Atenção Primária à saúde através das oficinas de gestantes, pré-natal e puericultura qualificada, podendo o tema do Aleitamento Materno ser discutido com as mães buscando entender a situação vivenciada por elas. A Rede Cegonha é uma estratégia do Ministério da Saúde fundamentada nos princípios da humanização e assistência, com foco no pré-natal, parto e puericultura. É nesse contexto que o estudo visa ressaltar a importância da escuta qualificada com a finalidade de melhorar e humanizar a assistência à saúde.

Muitas mães se encontram na grande expectativa que é cuidar de um novo ser, e a preparação de todas as fases, ainda no período da gestação, é de extrema importância, para o sucesso no aleitamento:

Pra amamentar existe um preparo antes até da criança nascer né, eu comecei uma preocupação antes que era preparar o seio. (M3)

Os primeiros momentos de vínculo da mãe com o bebê, ainda na maternidade, são momentos únicos e de muitas novidades, que segundo as entrevistadas representaram experiências exitosas:

[...] ainda na maternidade quando colocou no peito ela já sugou muito direitinho. Então pra mim não foi difícil, eu tinha muito leite, ela pegou rapidinho. (M4)

A dúvida e a insegurança representa um ponto que dificulta no aleitamento materno podendo levar, em alguns casos, na alimentação precoce de outros leites que não somente o da mãe:

Dificuldade que eu tenho é ai meu Deus será que comeu direito, porque a gente nunca sabe a quantidade de leite que mamou, na mamadeira você vê a quantidade, então você será que foi suficiente... será que tá pegando direito. (M10)

Vários estudos revelam que as dificuldades mais relatadas pelas mães são: a escassez ou falta de leite; o fato de os filhos não quererem ou não aceitarem mais o peito; dificuldades como rachaduras, fissuras, sangramentos, dores; doença da mãe; e o cansaço, devido contato prolongado com o bebê no seio. ${ }^{7,18,20}$

As mães desse estudo relatam que a dor, as fissuras e o cansaço foram os maiores obstáculos no ato de amamentar:

Meu peito feriu, rachou, infeccionou, pe-
drou... Eu perdi parte do bico do meu peito,
fiquei com constipação, e ele passava horas
mamando, o dia inteiro... 40, 50 minutos no
peito, botava no outro, eu realmente fiquei
muito cansada, mas eu tinha bastante leite.
(M1)

Segundo uma pesquisa realizada com o objetivo de identificar os fatores relacionados ao desmame precoce entre os menores de seis meses de vida, verificou-se que a dor é uma das principais causa da maioria dos problemas na amamentação, uma vez que interfere no reflexo da ejeção 
do leite e consequentemente a criança não consegue mamar e a mãe revela o sentimento de angustia, que pode levar a uma amamentação mal sucedida e interrompida precocemente. $^{7}$

No começo eu tive aquela dificuldade que toda mãe tem, porque dói demais e fica chorando... e eu acho que no começo é como se não tivesse leite suficiente pra ele e você fica naquele desespero que ele mama e sempre quer mais... no começo foi tudo bem dificil. Meu peito ficava carne viva. Sabe, chega eu suava frio. (M14)

\subsection{Vivências e sentimentos}

Conhecer as vivências e os sentimentos é interessante uma vez que oferece subsídios para aproximar a intervenção prestada às necessidades relatadas pelas mães, o que poderá influenciar posteriormente no aleitamento materno por um tempo mais prolongado e prazeroso.

O PET-saúde/Rede Cegonha procura através de suas atividades a interação ensino e serviço, contribuindo na formação acadêmica, na assistência à saúde maternoinfantil e principalmente contribuindo gerando novos olhares para os profissionais de saúde, criando possibilidades e soluções cabíveis para a melhoria na qualidade dos serviços e assistência.

É muito prazeroso amamentar. Meu sentimento, foi de alegria mesmo, primeiro por ter conseguido... então a primeira mamada dele eu me senti assim realizada. (M8)

A relação da mãe com seu filho é, em geral, um sentimento presente na mulher porque a convivência diária, desde a concepção, cria vínculos significativos que os aproximam. 16

Um dos fatores para o sucesso do aleitamento é o desejo da mãe, demonstrado durante gestação, de amamentar seu filho no peito. ${ }^{18}$
O apoio familiar, incentivo de amigos, e a carga emocional interferem no aleitamento materno. Mulheres entrevistadas no período puerperal revelaram a necessidade de outra pessoa para ajudar, esclarecer e acompanhar. Os familiares e pessoas significativas devem agir como fontes de ajuda, e os profissionais de saúde, principalmente os de enfermagem e pediatras, como fontes de informação. ${ }^{9}$

Eu acabei demorando muito pra procurar ajuda pra resolver o problema, porque o pai do meu bebê mora em Brasília e eu moro aqui. Então a gente teve essa dificuldade da distância. Eu queria ficar aqui por causa do apoio da minha mãe, da minha família, dos meus amigos. (M1)

Em outro estudo evidenciou-se que a mulher no ciclo gravídico puerperal necessita de apoio social, profissional e familiar, sendo o pai o principal suporte. ${ }^{17}$

O aleitamento materno é a primeira prova de amor da mãe pelo filho, pois engendra sentimentos de prazer físicos e morais. A mãe é a principal dispensadora de amor para o recém-nascido e o bebê. ${ }^{16}$

É o alimento, é você quem dá, eu acho que assim, fortalece muito mais o vínculo, a gente já ama, e amamentando eu acho que assim um momento mágico. (M4)

$\mathrm{Na}$ tentativa de incentivar a amamentação, muitas campanhas trazem como slogan "amamentar é um ato de amor" e, na lógica descrita anteriormente, prover alimento aos filhos é possível apenas para as mulheres. Esse tipo de abordagem pode ser prejudicial, uma vez que impõe exclusivamente à mãe um fardo que deveria ser dividido com seu companheiro, familiares e profissionais de saúde ${ }^{11}$

[...] eu tinha que amamentar, eu tinha que conseguir amamentar minha filha a qualquer custo, era o meu ato de amor por ela. 
Aleitamento materno: desmistificando esse ato de amor como uma abordagem na promoção da saúde

Acho que psicologicamente eu fui muito impactada pelas campanhas. (M9)

De acordo com as entrevistadas o uso de medicações para cicatrização e algumas medidas populares foram os caminhos mais utilizados para que as mães não deixassem de amamentar seus filhos:

Eu usei pomada, passava o leite do próprio peito que o pessoal indicava... dava uma melhorada muito boa mesmo. (M5)

[...] a gente vai pra sabedoria popular né, ai lasca a casquinha de banana que dá certo, super certo. (M11)

Dessa forma é importante, durante conversas com as mães, identificar os conhecimentos, as crenças, experiências anteriores e as atitudes da gestante em relação à amamentação. ${ }^{8}$

Os profissionais de saúde tem sólida formação acadêmica para atuar no desenvolvimento de programas de promoção da saúde. ${ }^{12}$ Sendo responsável pela a atenção integral ao usuário, não só do ponto de vista físico, como também social, ético e humano. ${ }^{19}$

Tem como função, na saúde materno-infantil, apoiar as gestantes, escutandoas, esclarecendo suas dúvidas, preocupações e favorecendo a troca de experiências, 15 oferecendo assim uma saúde mais integral e humanizada.

Existem oficinas voltadas para o cuidado e a preparação da amamentação, que devem ter como temas a interferência da alimentação artificial, uso de mamadeiras, a importância da livre demanda, a rotina da mamada, ${ }^{15}$ a associação entre fissura mamilar e interrupção precoce do aleitamento, ${ }^{22}$ além das posturas corretas da mãe e do bebê e de outros assuntos como o parto, auto-estima, relação com o marido e com a família.
Tem um programa de gestantes, mas é da empresa e é muito bacana, se você ver, é muito rico mesmo, todo mês você tem um encontro e fala sobre tudo a auto estima, o seu relacionamento em casa com o marido, sua alimentação, uma caminhada, a sua saúde viu, só fui uns três, mas achei muito bacana foi o que ajudou. (M15)

O uso de outras alimentações que não o leite materno e a utilização do leite de fórmula é prejudicial para o sucesso do aleitamento materno exclusivo, apesar de algumas mães relataram que tiverem a necessidade de incluir esse leite ou por recomendação médica ou por necessidade própria, todavia, essa utilização ocorre de maneira inadequada, na maioria das vezes:

Eles compraram o leite e começaram a dar pra ela, e assim, depois a gente ficou sabendo que não era pra ter dado na mamadeira era pra ter dado pelo menos em colherzinha, copinho, seringa, [...] o pediatra dela disse... é um dos erros gravíssimos... se tivesse dado ela não teria rejeitado o peito. (M2)

\subsection{A hora do desmame}

A Organização Mundial da Saúde (OMS) e o Ministério da Saúde recomendam aleitamento materno exclusivo por seis meses e complementado até os dois anos ou mais. Segundo a OMS não há vantagens em se iniciar os alimentos complementares antes dos seis meses, podendo, inclusive, haver prejuízos à saúde da criança. ${ }^{4}$

A média de tempo de amamentação exclusiva das mães entrevistadas foram de 4 meses, poucas conseguiram amamentar até os 6 meses e algumas não conseguiram alcançar os 4 meses:

Ela só mamou até 4 meses porque eu tive que voltar a trabalhar. (M15).

Apesar da importância e da recomendação do AME nos primeiros 6 meses 
Aleitamento materno: desmistificando esse ato de amor como uma abordagem na promoção da saúde

de vida do lactente, esse padrão de aleitamento materno (AM) ainda é pouco praticado no Brasil. ${ }^{22}$

\section{[...] exclusivo foi só os 2 primeiros meses. É pela questão do retorno ao trabalho mesmo que ele queria ir preparando a ne- ném. (M11) \\ Quando completou os 4 meses que eu tive que voltar a trabalhar, dei o incentivo. (M10)}

Contudo, ainda que muitos dos fatores apresentados pelas depoentes deste estudo pareçam explicar as causas do desmame precoce, como: problemas relacionados à "falta de leite", problemas das mamas e a recusa do bebê em pegar o peito e o crescimento da participação feminina no mercado de trabalho, é possível sugerir outras razões que o expliquem, ligadas ao ambiente, à personalidade materna, às suas emoções, à relação com o marido e a família, às influências culturais e à sua resposta aos diferentes problemas do cotidiano. ${ }^{2}$

Constatou-se que embora a totalidade de mães pesquisadas reconheçam a importância do leite materno, seis mães amamentaram exclusivamente seus filhos no máximo por três meses, o contrário do esperado. $^{2}$

E segundo as mães o desmame precoce acontecia pelos próprios bebes que não queria mais ou devido a facilidade da fórmula e a distância da mãe:

[...] quando chegava em casa ela já acostumada de comer as outras refeições, as outras comidas, ai ela mesmo não foi querendo. (M15)

Apesar da importância do AM para a criança, a mãe, a família e a sociedade, as taxas de amamentação no Brasil são baixas, em especial a do aleitamento materno exclusivo (AME) até os seis meses. ${ }^{1}$
Somente duas mães continuam amamentando e duas seguiram a recomendação do AME até o $6^{\circ}$ mês.

\section{CONSIDERAÇÕES FINAIS}

Observou-se que entre as dificuldades encontradas destaca-se a dor, seguidas pelas rachaduras, fissuras, cansaço e a produção reduzida de leite.

A desinformação ou a falta de compreensão apontam para o valor da Educação em Saúde e da aproximação cultural entre profissionais e pacientes para permear a comunicação. Fazendo-se necessário uma assistência humanizada das mães, pois muitas vezes elas não sabem o que fazer e sentem-se sem apoio até mesmo da família. Desta forma, recomenda-se que as práticas de promoção, proteção e apoio ao aleitamento materno sejam ampliadas desde o momento do pré-parto.

Assim a importância desse trabalho foi de despertar à todos da área da saúde na importância de estimular, orientar e de conversar com as gestantes, puérperas e mães sobre essa prática com a finalidade de favorecer um período mais prolongado e prazeroso do AME.

\section{REFERÊNCIAS}

1. Alves BA, Cursi J, Labegalini MPC, Higarashi IH, Bercini LO. Mães com aleitamento materno exclusivo em centro de educação infantil no local de trabalho. Rev. Rene. 2009; 10(3);27-36.

2. Araújo OD, Cunha AL, Lustosa LR, Nery IS, Mendonça RCM, Campelo SMA. Aleitamento materno: fatores que levam ao desmame precoce. Rev Bras Enferm, 2008; 61(4): 488-92.

3. Bardin L. Analise de Conteúdo. 19. ed. Lisboa/ Portugal: Edições 70, 2008. 
4. Brasil. Ministério da Saúde. Saúde da Criança: Nutrição Infantil Aleitamento Materno e Alimentação Complementar. Caderno de Atenção Básica, $n^{0}$ 23, 2009.

5. Brasil. Portaria n. 1.459, de 24 de junho de 2011. Institui, no âmbito do Sistema Único de Saúde - SUS - a Rede Cegonha. Disponível em: http://bvsms.saude.gov.br/bvs/saudeleg is/gm/2011/prt1459_24_06_2011.html

6. Brasil. Resolução CNS n ${ }^{\circ} 466$, de 12 de Dezembro de 2012. Aprova diretrizes e normas regulamentadoras de pesquisa envolvendo seres humanos. Diário Oficial da União, Brasília, n. 12, p. 59, 13 jun. 2013. Seção 1.

7. Frota MA, Costa FL, Soares SD, Filho OAS, Albuquerque CM, Casimiro CF. Fatores que interferem no aleitamento materno. Rev. Rene. 2009; 10 (3); 6167.

8. Garcia MMR, Santos JG, Lima SS, Ferrari R. O conhecimento das puérperas sobre preparo das mamas e aleitamento materno. Revista Eletrônica Gestão \& Saúde. 2013; 04 (1); 16841698.

9. Gonçalves AR. Aprender a ser mãe. Processos de aprendizagem de mães primíparas durante os primeiros dois meses pós-parto. Sísifo - Rev Ciênc da Educação 2008;5:59-68.

10. Gradim CVC, Magalhães MC, Faria MCF, Arantes CIS. Aleitamento materno como fator de proteção para o câncer de mama. Rev Rene. 2011; 12(2):358-64.

11. Ichisato SM, Shimo AK. Revisiting early weaning through historical analysis. Rev Latino-Am Enfermagem 2002;10:578-85.
12. Manhães JSF, Pereira NF, Fernandes SC, Alves AS, Sousa LLC, Shimoda E. Fisioterapia e educação em saúde: relação entre gravidez precoce e o bebê de risco Adolesc. Saude, 2011; 8(3):2734.

13. Marques ES, Cotta RMM, Priore SE. Mitos e crenças sobre o aleitamento materno. Ciênc. saúde coletiva. 2011;16 (5):2461-68.

14. Martins, RFM, Filho RHLL, Fernandes FSF, Fernandes JKB. Amamentação e fatores relacionados ao desmame precoce: uma revisão crítica de literatura. Rev Pesq Saúde. 2012; 3 (13); 47 52.

15. Nascimento VC, Oliveira MIC, Alves $\mathrm{VH}$, Silva KS. Associação entre as orientações pré-natais em aleitamento materno e a satisfação com o apoio para amamentar. Rev. Bras. Saúde Matern. Infant. 2013; 13 (2); 147-159.

16. Osório CM, Queiroz ABA. Representações sociais de mulheres sobre a amamentação: Teste de associação livre de idéias acerca da interrupção precoce do aleitamento materno exclusivo. R. enferm. 2007; 11(2); 261-7.

17. Pereira RSV, Oliveira MIC, Andrade CLT, Brito AS. Fatores associados ao aleitamento materno exclusivo: o papel do cuidado na atenção básica. Cad. Saúde Pública. 2010;26(12):2343-2354.

18. Rocha NB, Garbin AJI, Garbin CAS, Moimaz SAS. O ato de amamentar: um estudo qualitativo. Physis Revista de Saúde Coletiva. 2010; 20 (4); 12931305.

19. Silva ID, Silveira MFA. A humanização e a formação do profissional em fisioterapia. Ciência \& Saúde Coletiva, 2011(1):1535-1546. 
20. Teixeira MM, Vasconcelos VM, Silva DMA, Martins EMCS, Martins MC, Frota MA. Percepções de primíparas sobre orientações no pré-natal acerca do aleitamento materno. Rev Rene. 2013; 14(1);179-86.

21. Toma ST, Rea MF. Benefícios da amamentação para a saúde da mulher e da criança: um ensaio sobre as evidências Cad. Saúde Pública, 2008; 24(2): 235-246.

22. Vieira GO, Martins CC, Vieira TO, Oliveira NF, Silva LR. Fatores preditivos da interrupção do aleitamento materno exclusivo no primeiro mês de lactação. Jornal de Pediatria. 2012; 86 (5); 441- 44.

\footnotetext{
ABSTRACT

Breastfeeding: demystifying love that act as a focus on health promotion

Objective: Analyze the difficulty that affect the practice the breastfeeding experience for mothers. Methodology: It was accomplished a descriptive study with a qualitative approach. That study
}

was developed in a private university in Fortaleza - Ceará. To collect information, was applied a sociodemographic questionnaire and a semistructured interviews that happed during August and October of 2013. The data were analyzed according to the theory of thematic content analysis proposed for Bardin. Results: Fifteen mothers aged between 26 and 40 years from different socioeconomic and cultural profiles participated in the study. It was noted from the maternal speeches highlights three categories: Discovering the act of breastfeeding; Experiences and feelings; and The time to weaning. Conclusion: The most common difficulties faced for mothers are pain, followed by cracks, fissure, fatigue and reduced breast milk production. The duration of breastfeeding of interviewees mother was less than recommended from Ministry of Health.

Descriptors: Breastfeeding, Emotions, Weaning 